\section{Immunopathogenesis of conjunctival scarring in trachoma}

AHMED M. ABU EL-ASRAR, KAREL GEBOES, KHALID F. TABBARA, SOLIMAN A. AL-KHARASHI, LUC MISSOTTEN, VALEER DESMET

\section{Abstract}

Purpose Trachoma, a chronic follicular conjunctivitis caused by infection with Chlamydia trachomatis, is the leading cause of preventable blindness. The blinding complications are associated with progressive conjunctival scarring that may result from immunologically mediated responses. We studied the processes involved in the regulation of inflammation and fibrosis in trachoma by investigating the expression of fibrogenic cytokines in the conjunctiva. Methods We studied conjunctival biopsy specimens obtained from nine subjects with active trachoma and from four control subjects. We used immunohistochemical techniques and a panel of monoclonal and polyclonal antibodies directed against interleukin-1 $\alpha$ (IL-1 $\alpha)$, interleukin-1 $\beta$ (IL-1 $\beta)$, tumour necrosis factor- $\alpha$ (TNF- $\alpha$ ) and plateletderived growth factor (PDGF). In addition, we characterised the composition of the inflammatory infiltrate by the use of a panel of monoclonal antibodies. Sirius red and Van Gieson stains were used to characterise the extent of fibrous tissue in the substantia propria.

Results Trachoma specimens showed greater numbers of inflammatory cells than control specimens. The expression of cytokines was absent in the normal conjunctiva. Cytoplasmic IL- $1 \alpha$ and IL-1 $\beta$ expression was noted in the conjunctival epithelium in all trachoma specimens. IL-1 $\alpha$, IL-1 $\beta$, TNF- $\alpha$ and PDGF were detected in macrophages infiltrating the substantia propria. B lymphocytes predominated over $\mathrm{T}$ lymphocytes in six trachoma biopsies with fibrosis confined to the deep substantia propria, whereas $T$ lymphocytes predominated over B lymphocytes in three biopsies with more extensive fibrosis. In all trachoma biopsies helper/inducer $\mathrm{T}$ lymphocytes outnumbered suppressor/cytotoxic T lymphocytes.

Conclusions The upregulated local production of IL-1 $\alpha$, IL- $\beta$, TNF- $\alpha$ and PDGF might contribute to conjunctival damage and scarring in trachoma.
Key words Chlamydia, Conjunctiva, Cytokines, Fibrosis, Trachoma

Trachoma, the world's leading infectious cause of blindness, is estimated to affect 500 million people, 7 million of whom are blind. ${ }^{1}$ It is caused by serovars A, B, Ba and C of Chlamydia trachomatis. ${ }^{2}$ In its early (active) stage, which is seen principally among children in endemic areas, it is characterised by a chronic follicular conjunctivitis which affects principally the upper tarsal conjunctiva. Among older individuals in endemic areas, conjunctival scarring replaces the follicles and may lead to entropion, trichiasis and corneal blindness.

The pathological mechanisms by which trachoma causes conjunctival scarring are unclear. Although the growth of $C$. trachomatis is restricted to the epithelium, the consequences of infection, namely conjunctival and subconjunctival scarring, can lead to dry eye syndrome, entropion and trichiasis. In previous immunohistochemical studies we have demonstrated that the conjunctival biopsies from children with active trachoma showed an intense epithelial inflammatory infiltrate consisting of macrophages, $\mathrm{T}$ lymphocytes and dendritic cells. The stromal inflammatory infiltrate was organised as B lymphoid follicles, and there was also a diffuse infiltrate consisting of $B$ lymphocytes, $\mathrm{T}$ lymphocytes, macrophages, dendritic cells and plasma cells in which $\operatorname{IgA}^{+}$ cells were most prevalent. In addition we have shown that the superficial epithelial cells infected with C. trachomatis expressed major histocompatibility complex (MHC) class II antigens, which may render these cells capable of acting as antigen presenting cells, thereby enhancing the immune response.,

Prevention of trachoma-induced damage to the ocular surface requires an understanding of the factors that promote conjunctival tissue destruction and fibrosis in trachoma. Therefore, using immunohistochemical methods we examined the in situ expression of the fibrogenic cytokines interleukin- $1 \alpha$ (IL- $1 \alpha)$, interleukin-1 $\beta$ (IL-1 $\beta)$, tumour necrosis factor- $\alpha$ (TNF- $\alpha$ ) and platelet-derived growth factor (PDGF) in
A.M. Abu El-Asrar

K.F. Tabbara

S.A. Al-Kharashi

Department of

Ophthalmology

King Abdulaziz University

Hospital

Airport Road

PO Box 245

Riyadh 11411

Saudi Arabia

Fax: +966-1-4775741

K. Geboes

$\checkmark$. Desmet

Laboratory of

Histochemistry and

Cytochemistry

University Hospital

St Rafael

Leuven

Belgium

L. Missotten

Department of

Ophthalmology

University Hospital

St Rafael

Leuven

Belgium 
Table 1. Monoclonal and polyclonal antibodies used in this study

\begin{tabular}{llll}
\hline Antibody & Specificity & Working dilution & Source $^{\text {a }}$ \\
\hline Anti-IL-1 $\alpha$ & IL-1 $\alpha$ & $1: 10$ & Oncogene Science \\
Anti-IL-1 $\beta$ & IL-1 $\beta$ & $1: 10$ & Oncogene Science \\
Anti-PDGF (pc) & PDGF & $1: 10$ & Oncogene Science \\
Anti-TNF- $\alpha$ (pc) & TNF- $\alpha$ & $1: 10$ & Innogenetics \\
L26 $^{+}$ & Pan-B cells & $1: 100$ & Dakopatts \\
$\mathrm{OKT}_{4}{ }^{+}$ & T helper/inducer cells & $1: 20$ & Ortho Diagnostics \\
Leu3a $^{+}$ & T helper/inducer cells & $1: 5$ & Becton-Dickinson \\
$\mathrm{OKT}_{8}{ }^{+}$ & T cytotoxic/suppressor cells & $1: 10$ & Ortho Diagnostics \\
$\mathrm{KP}_{1}^{+}$ & Macrophages & $1: 50$ & Dakopatts \\
\hline
\end{tabular}

IL-1, interleukin 1; PDGF, platelet derived growth factor; TNF, tumour necrosis factor; (pc), polyclonal antibodies.

${ }^{a}$ Oncogene Science, Cambridge, MA, USA; Innogenetics, Gent, Belgium; Dakopatts A/S, Copenhagen, Denmark; Ortho Diagnostics, Raritan, NJ, USA; Becton-Dickinson, Sunnyvale, CA, USA.

conjunctival biopsy specimens from patients with active trachoma and related the observations to the inflammatory infiltrate. These cytokines were selected on the basis of a large body of data demonstrating their importance for the induction of fibrosis.

\section{Patients and methods}

\section{Study subjects and specimen collection}

School children in a village in the Eastern province of Saudi Arabia were examined using a binocular magnifying loupe $(4 \times$ magnification $)$ and a portable light source. The diagnosis of active trachoma and the grading system of the intensity of the disease were performed using the recommended World Health Organization criteria. ${ }^{1}$ A total of nine children with active trachoma between 7 and 16 years of age were included in the study (mean age 9.4 years). All patients were asymptomatic and had mild to moderate active trachoma. A $2 \times 2 \mathrm{~mm}$ upper palpebral conjunctival biopsy specimen was obtained from each patient. None of the patients was on topical therapy prior to the biopsy. The study was approved by the Research Center, College of Medicine, King Saud University and the parents of patients admitted to the study gave their informed consent. In addition, four upper palpebral conjunctival biopsy specimens were obtained from patients undergoing strabismus surgery without obvious inflammation and served as controls. The control patients were in a similar age group.

\section{Immunohistochemical staining}

The conjunctival biopsy specimens were immediately snap-frozen in Tissue-Tek optimum cutting temperature (OCT) compound (Miles Laboratories, Indiana) and maintained at $-80{ }^{\circ} \mathrm{C}$ until use. For

immunohistochemistry, $5 \mu \mathrm{m}$ serially cut cryostat sections were dried overnight at room temperature, fixed in absolute acetone for $10 \mathrm{~min}$ and stained with a threestep avidin/biotin peroxidase-labelled complex procedure. Rehydrated slides were incubated for $30 \mathrm{~min}$ with the monoclonal and polyclonal antibodies listed in Table 1, which were diluted to an optimum concentration. The secondary and tertiary antibodies consisted of biotin-conjugated rabbit anti-mouse immunoglobulin and the avidin/biotin peroxidaselabelled complex, respectively, both purchased from Dakopatts (Copenhagen, Denmark). All incubations were carried out for $30 \mathrm{~min}$ at room temperature, then washed in three changes of phosphate-buffered saline at pH 7.2 for $15 \mathrm{~min}$. The reaction product was visualised by incubation for $10 \mathrm{~min}$ in $0.05 \mathrm{M}$ acetate buffer at $\mathrm{pH}$ 4.9 , containing $0.05 \%$ 3-amino-9-ethyl-carbazole and $0.01 \% \mathrm{H}_{2} \mathrm{O}_{2}$, resulting in bright-red immunoreactive sites. The slides were faintly counterstained with Harris haematoxylin. Finally, the sections were rinsed with distilled water and coverslipped with glycerol. Controls, which were invariably negative, consisted of omission of primary or secondary antibody and use of chromogen alone.

Cells were counted in five representative fields. We used an eyepiece calibrated grid with $\times 25$ magnification. With this magnification and calibration, we counted the cells present in an area of $0.155 \times 0.155 \mathrm{~mm}$. Means \pm standard deviations were calculated for each cell type in trachoma and control specimens. Student's $t$-test was used to analyse the statistical significance of differences between mean values. The differences were considered significant if the $p$ value was $<0.05$.

To characterise the extent of fibrous tissue and collagen formation in the substantia propria, sirius red and Van Gieson staining were used.

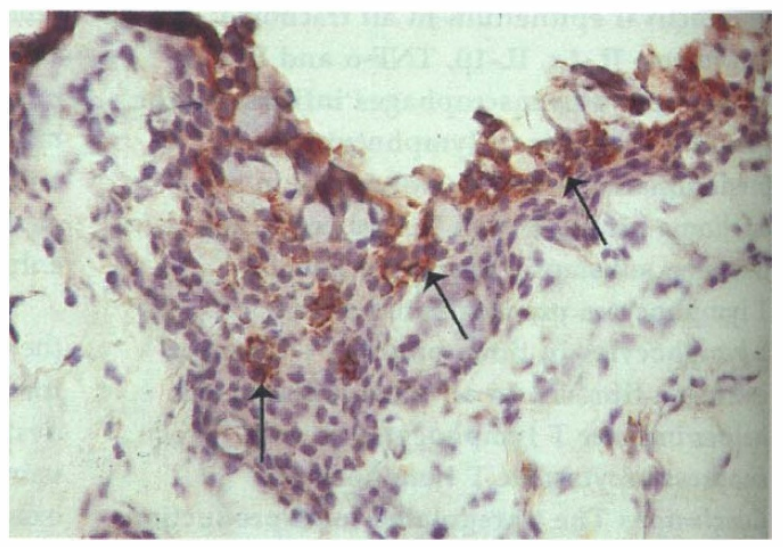

Fig. 1. Anti-IL-1 $\alpha$ staining shows cytoplasmic $I L-1 \alpha$ expression in the superficial epithelial layers (arrows) (three-step avidin/biotin peroxidase-labelled complex procedure; $\times 300)$. 


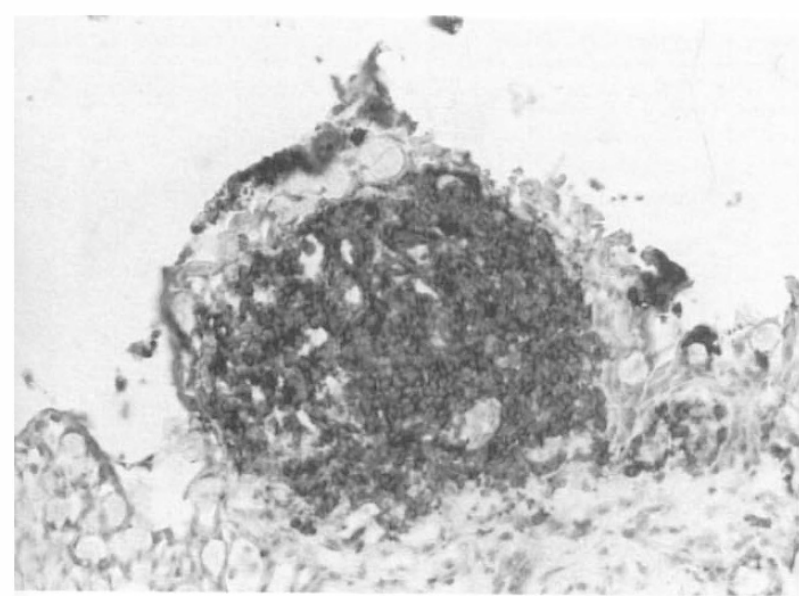

(a)

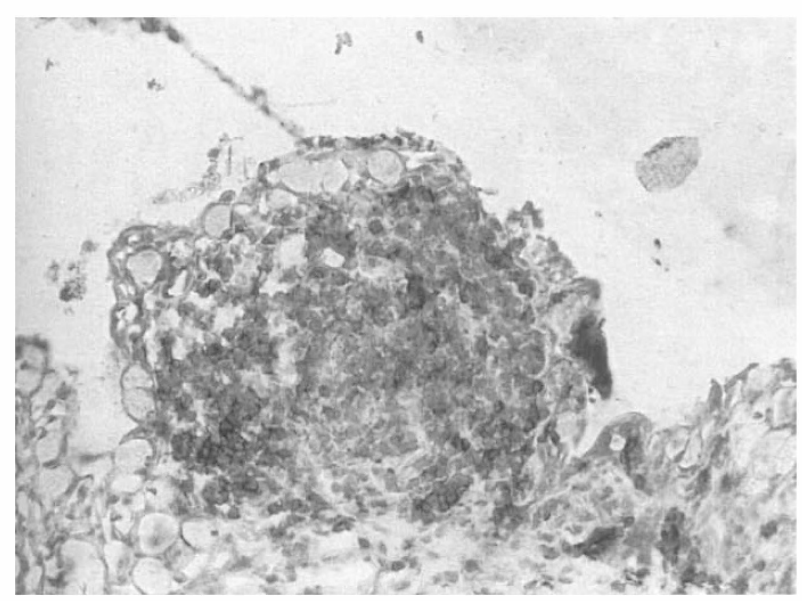

(c)

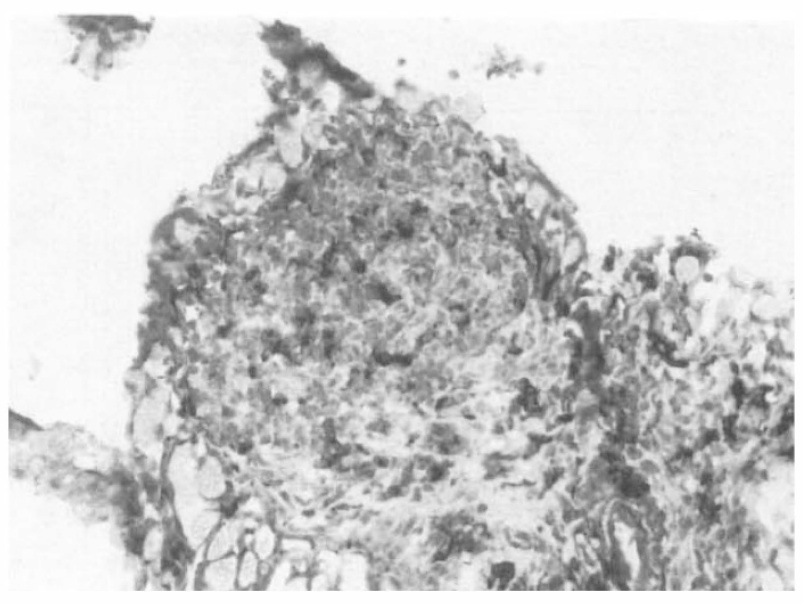

(b)

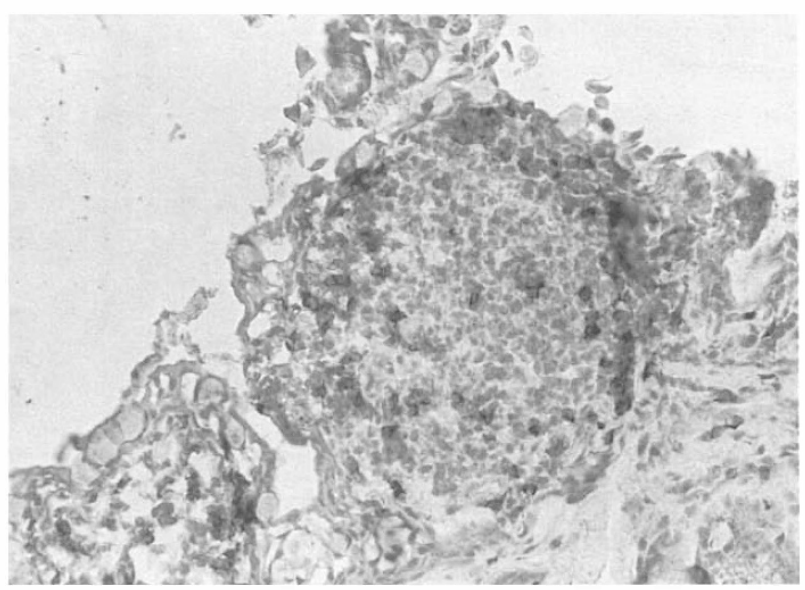

(d)

Fig. 2. Frozen serial section immunohistochemical staining. (a) $\mathrm{L}_{2} 6^{+} \mathrm{B}$ lymphocytes. (b) $\mathrm{KP}_{1}^{+}$macrophages. (c) OKT ${ }_{4}$-Leu3a ${ }^{+}$helper/inducer $\mathrm{T}$ lymphocytes. (d) $\mathrm{OKT}_{8}{ }^{+}$suppressor/cytotoxic $T$ lymphocytes. Note that the lymphoid follicle is composed mostly of L26 ${ }^{+} B$ lymphocytes and that $\mathrm{OKT}_{4}$-Leu3a ${ }^{+}$helper/inducer $\mathrm{T}$ lymphocytes predominated over $\mathrm{OKT}_{8}^{+}$suppressor/cytotoxic $\mathrm{T}$ lymphocytes (three-step avidin/biotin peroxidaselabelled complex procedure; $\times 300)$.

\section{Results}

The cells counts are presented in Table 2. Trachoma specimens as a whole showed higher counts than control specimens for $\mathrm{L}_{26}{ }^{+}, \mathrm{OKT}_{4}$-Leu3a ${ }^{+}, \mathrm{OKT}_{8}{ }^{+}$and $\mathrm{KP}_{1}{ }^{+}$cells (Table 3). The expression of IL- $1 \alpha$, IL-1 $\beta$, TNF- $\alpha$ and PDGF was absent in the normal conjunctiva.

The epithelial inflammatory infiltrate in trachoma specimens consisted of a few $\mathrm{OKT}_{4}$-Leu3a ${ }^{+}$helper/ inducer $\mathrm{T}$ lymphocytes, $\mathrm{OKT}_{8}{ }^{+}$suppressor/cytotoxic $\mathrm{T}$ lymphocytes, and $\mathrm{KP}_{1}{ }^{+}$macrophages. All epithelial cells showed cytoplasmic expression of IL- $1 \alpha$, which was most intense in the superficial epithelial layers (Fig. 1). Patchy, less intense cytoplasmic staining was noted for IL-1 $\beta$ mainly in the superficial epithelial layers.

In the substantia propria of trachoma specimens, the inflammatory infiltrate was organised as a diffuse infiltrate and as small lymphoid follicles without reactive centres. These lymphoid follicles were noted in six specimens and were absent in three specimens (nos. 1, 6 and 7; Table 2). The infiltrate was most intense in the area just underneath the epithelium and in the perivascular areas. The diffuse infiltrate was mixed in composition and consisted of $\mathrm{OKT}_{4}$-Leu3a ${ }^{+}$helper/inducer $\mathrm{T}$ lymphocytes, $\mathrm{OKT}_{8}{ }^{+}$suppressor/cytotoxic $\mathrm{T}$ lymphocytes, $\mathrm{L}^{2} 6^{+} \mathrm{B}$ lymphocytes, and $\mathrm{KP}_{1}{ }^{+}$ macrophages. The lymphoid follicles consisted of large numbers of $\mathrm{L}^{2} 6^{+} \mathrm{B}$ lymphocytes, and smaller numbers of $\mathrm{OKT}_{4}$-Leu3a ${ }^{+}$helper/inducer $\mathrm{T}$ lymphocytes, $\mathrm{OKT}_{8}{ }^{+}$ suppressor/cytotoxic $\mathrm{T}$ lymphocytes and $\mathrm{KP}_{1}^{+}$ macrophages. In all specimens $\mathrm{OKT}_{4}-\mathrm{Leu}_{3} \mathrm{a}^{+}$helper/ inducer $\mathrm{T}$ lymphocytes predominated over $\mathrm{OKT}_{8}{ }^{+}$ suppressor/cytotoxic T lymphocytes (Fig. 2).

In the substantia propria of trachoma specimens, mononuclear cells expressing cytoplasmic IL- $1 \alpha$, IL-1 $\beta$, TNF- $\alpha$ and PDGF were noted (Fig. 3). These cells were judged to be macrophages because they showed coexpression of $\mathrm{KP}_{1}$ marker in serial sections.

Sirius red and Van Gieson staining for fibrous tissue were localised around blood vessels in the substantia propria in control specimens. In trachoma biopsies with prominent lymphoid follicles sirius red and Van Gieson staining were prominent in the deep substantia propria. In these biopsies $\mathrm{L}^{2} 6^{+} \mathrm{B}$ lymphocytes predominated over $\mathrm{T}$ lymphocytes. In trachoma conjunctival biopsy specimens without lymphoid follicles sirius red and Van Gieson staining were more pronounced and involved the 


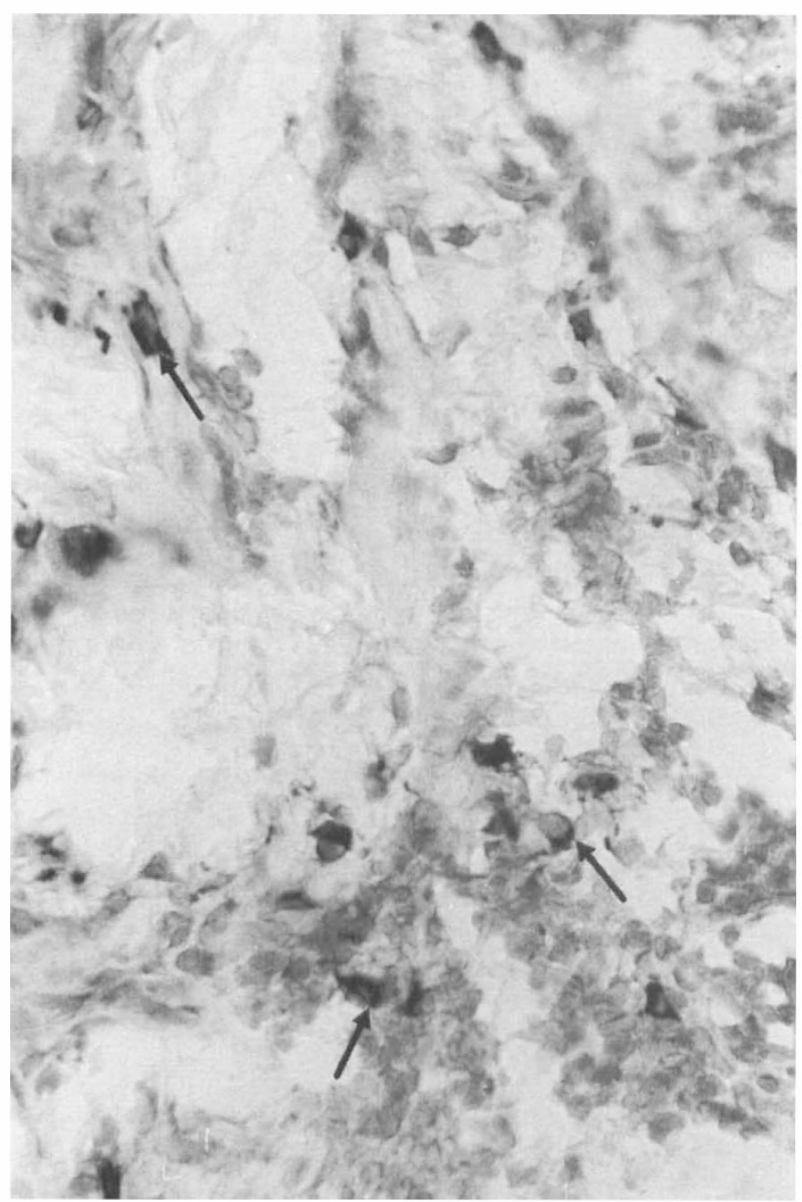

(a)

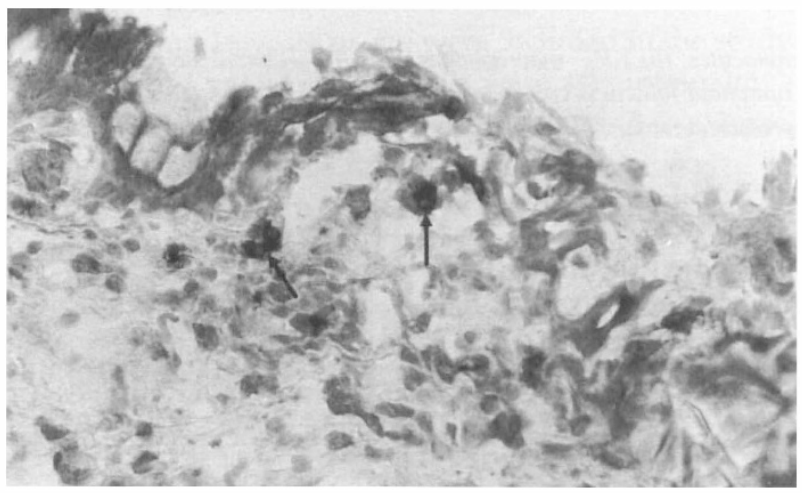

(c)

whole substantia propria starting immediately under the epithelium. In these biopsies $\mathrm{T}$ lymphocytes predominated over $\mathrm{L}^{2} 6^{+} \mathrm{B}$ lymphocytes.

\section{Discussion}

\section{IL-1 and trachoma}

Cytokine production during infection may play an important role in modulating host defences to C. trachomatis. This may also be a factor in the perpetuation of the inflammation and subsequent fibrosis. In the present study we have demonstrated that the conjunctival epithelial cells from patients with trachoma showed cytoplasmic expression of IL-1 $\alpha$ and IL-1 $\beta$. Normally, conjunctival epithelial cells do not

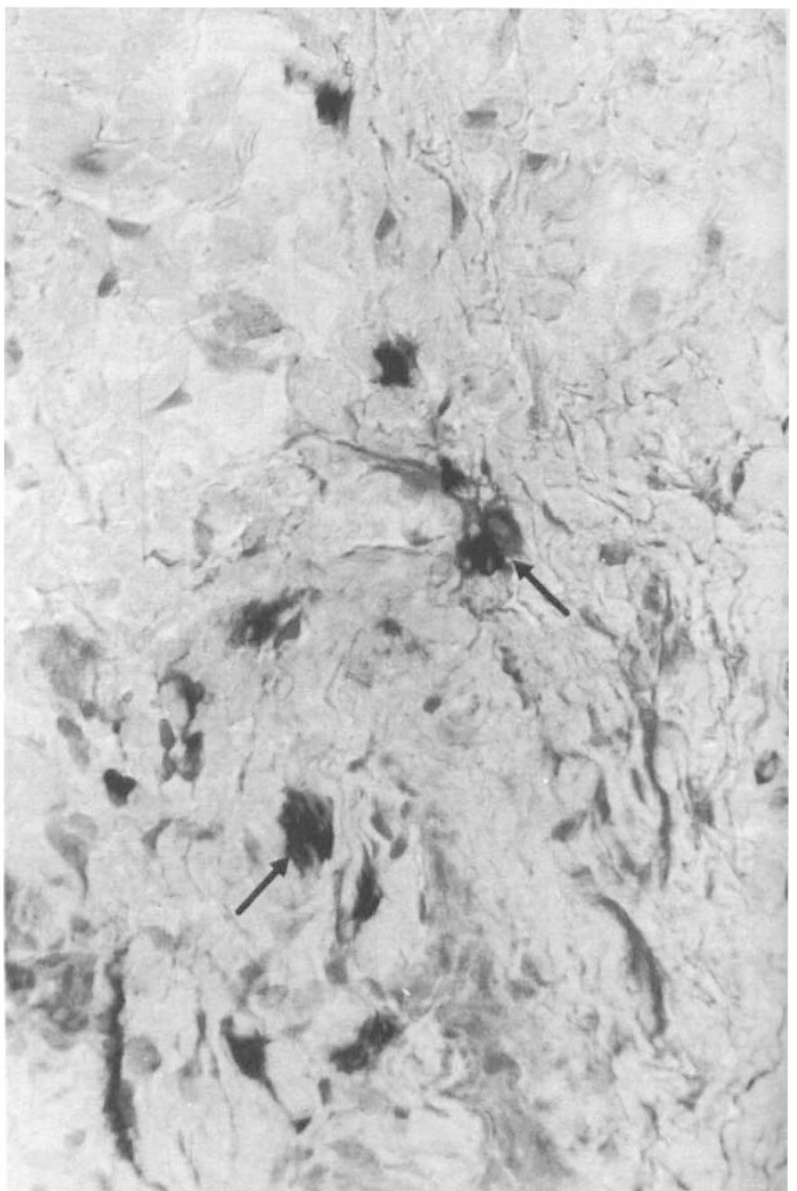

(b)

Fig. 3. Frozen section immunohistochemical staining. (a) Anti-IL-1 staining. (b) Anti-PDGF staining. (c) Anti-TNF- $\alpha$ staining. Note the intense labelling of macrophages in the substantia propria (arrows) (three-step avidin/biotin peroxidase-labelled complex procedure; $\times 500$ ).

express IL-1. When comparing IL- $1 \alpha$ and IL-1 $\beta$ expression by the conjunctival epithelial cells, we observed that IL- $1 \alpha$ was present in greater amounts than IL- $1 \beta$. IL- $1 \alpha$ and IL- $1 \beta$ are differentially regulated at both the transcriptional and post-transciptional level, ${ }^{5}$ probably explaining this difference. This has contributed to the observation that IL-1 $\alpha$ remains cell-associated and acts on a cell-cell basis whereas IL-1 $\beta$ is secreted as paracrine mediator. ${ }^{6}$ These findings demonstrate the in vivo expression and production of IL-1 by the conjunctival epithelial cells in trachoma. This production of IL-1 may constitute an important contributing factor in the process of scarring in trachoma. IL-1 is a pleiotropic cytokine produced chiefly by monocytes and macrophages but also by cells of epidermal, epithelial, 
Table 2. Number ${ }^{a}$ of immune cells in trachoma and control specimens

\begin{tabular}{|c|c|c|c|c|c|c|c|c|}
\hline Patient no. & $\mathrm{L}^{2} 6^{+}$ & OKT4-Leu3a ${ }^{+}$ & $\mathrm{OKT}_{8}{ }^{+}$ & $\mathrm{KP}_{1}^{+}$ & IL- $1 \alpha^{\mathrm{b}}$ & IL-1 $\beta^{\mathrm{b}}$ & TNF- $\alpha$ & PDGF \\
\hline \multicolumn{9}{|l|}{ Trachoma } \\
\hline $1^{\mathrm{c}}$ & 69 & 62 & 37 & 86 & 22 & 10 & 9 & 11 \\
\hline 2 & 225 & 115 & 76 & 77 & 11 & 10 & 19 & 17 \\
\hline 3 & 160 & 58 & 28 & 75 & 22 & 6 & 11 & 6 \\
\hline 4 & 185 & 46 & 31 & 56 & 11 & 8 & 9 & 12 \\
\hline 5 & 110 & 52 & 25 & 102 & 16 & 5 & 10 & 20 \\
\hline $6^{c}$ & 75 & 120 & 81 & 84 & 25 & 19 & 30 & 20 \\
\hline $7^{c}$ & 44 & 68 & 15 & 46 & 11 & 10 & 23 & 9 \\
\hline 8 & 260 & 130 & 77 & 90 & 6 & 11 & 30 & 7 \\
\hline 9 & 125 & 78 & 32 & 70 & 8 & 8 & 7 & 12 \\
\hline \multicolumn{9}{|l|}{ Control } \\
\hline 1 & 15 & 13 & 12 & 25 & 0 & 0 & 0 & 0 \\
\hline 2 & 23 & 21 & 17 & 17 & 0 & 0 & 0 & 0 \\
\hline 3 & 25 & 10 & 18 & 20 & 0 & 0 & 0 & 0 \\
\hline 4 & 21 & 15 & 15 & 20 & 0 & 0 & 0 & 0 \\
\hline
\end{tabular}

IL-1, interleukin-1; TNF, tumour necrosis factor; PDGF, platelet-derived growth factor.

${ }^{\mathrm{a} C}$ Cells counted in an area of $0.155 \times 0.155 \mathrm{~mm}$.

${ }^{\mathrm{b}}$ Epithelial cytoplasmic expression.

${ }^{\mathrm{c}}$ No lymphoid follicles.

lymphoid and vascular origin. ${ }^{7}$ In addition, it has been shown, using northern hybridisation with oligonucleotide and cDNA probes, that cultured corneal epithelial cells expressed IL-1. ${ }^{8}$ Our results are consistent with the findings of Rothermel et al. ${ }^{9}$ that C. trachomatis induced IL-1 production by human blood monocytes. They showed that human blood monocytes produced detectable IL-1 when cultured with as little as $1 \mu \mathrm{g}$ of chlamydial protein per millilitre, which corresponded to $4-40$ chlamydiae per monocyte. This suggests that during low-grade or subclinical infections, which are characteristic of chlamydial disease, very few organisms may be sufficient to stimulate IL-1 production.

Furthermore, Magee and associates ${ }^{10}$ have demonstrated increased mRNA and bioactivity for IL-1 in murine lungs after chlamydial infection. The relevance of IL-1 to trachoma was also suggested by the detection of increased levels of IL-1 in the tears from children with active trachoma. ${ }^{9}$

As an inflammatory mediator, IL-1 affects tissue remodelling by inducing the production of collagenase $^{11,12}$ and collagen. ${ }^{13}$ Furthermore, IL-1 can stimulate fibroblast proliferation ${ }^{13-15}$ via the induction of PDGF. ${ }^{14}$ Excessive IL-1 production is thought to contribute to tissue damage and fibrosis in chronic inflammatory conditions such as pulmonary fibrosis ${ }^{16,17}$ and bone marrow fibrosis. ${ }^{18}$ The local constitutive production of IL- 1 by the conjunctival epithelial cells could serve for the paracrine stimulation of target cells

Table 3. Number of immune cells in trachoma and control specimens

\begin{tabular}{|c|c|c|c|}
\hline Cell type & Control $(n=4)$ & Trachoma $(n=9)$ & $p$ value \\
\hline $\mathrm{L} 26^{+}$ & $21.0 \pm 4.3$ & $139.2 \pm 73.9$ & 0.001 \\
\hline OKT4-Leu3a $^{+}$ & $14.8 \pm 4.6$ & $81.0 \pm 32.0$ & $<0.001$ \\
\hline $\mathrm{OKT}_{8}^{+}$ & $15.5 \pm 2.6$ & $44.7 \pm 25.7$ & 0.012 \\
\hline $\mathrm{KP}_{1}^{+}$ & $20.5 \pm 3.3$ & $76.2 \pm 17.2$ & $<0.001$ \\
\hline
\end{tabular}

Values are the mean \pm SD.

${ }^{\mathrm{a}}$ Cells counted in an area of $0.155 \times 0.155 \mathrm{~mm}$. such as fibroblasts, and induce exaggerated production and accumulation of subconjunctival fibrous tissue in patients with trachoma.

\section{Inflammatory cells and fibrosis}

The close association of mononuclear inflammatory cells including lymphocytes and macrophages and fibroblasts within inflammatory loci during fibroplasia and fibrogenesis has been demonstrated. ${ }^{19-21}$ Lymphocytes and macrophages precede the influx of fibroblasts into these sites and exist within the lesion as the fibroblasts infiltrate, divide and generate components of the extracellular matrix. In vitro studies have revealed that activated lymphocytes and macrophages are capable of generating cytokines that affect these fibroblast functions, including stimulation of fibroblast chemotaxis, proliferation and collagen synthesis. ${ }^{22}$

\section{T lymphocytes and trachoma}

Previous in vitro studies ${ }^{23,24}$ have shown that C. trachomatis stimulates B lymphocytes to profilerate and differentiate into immunoglobulin-secreting plasma cells. Our results indicate that the in vivo counterpart of this in vitro response consists of B lymphoid follicles, which were present in six conjunctival specimens. In these specimens the number of B lymphocytes was greater than $\mathrm{T}$ cells and the fibrosis was confined to the deep substantia propria. In three specimens lymphoid follicles were not detected and $\mathrm{T}$ lymphocytes outnumbered B cells. In these specimens fibrosis was more pronounced and involved the whole substantia propria, starting immediately under the epithelium. Our findings are supported by previous studies ${ }^{25,26}$ of lymphocyte subsets in adults with cicatricial trachoma that demonstrated predominance of $\mathrm{T}$ lymphocytes over $B$ cells. These observations suggest a role for $T$ lymphocytes in the genesis of conjunctival scarring in cicatricial trachoma. Several lines of evidence suggest 
that $\mathrm{T}$ lymphocytes play a direct role in the pathogenesis of fibrosis. ${ }^{27-29} \mathrm{~T}$ lymphocytes produce mediators including IL-2 and inteferon- $\gamma$ (IFN- $\gamma$ ) that trigger macrophage production of fibrogenic cytokines. Furthermore, $\mathrm{T}$ lymphocytes produce transforming growth factor- $\beta$ (TGF- $\beta$ ), which stimulates collagen synthesis. ${ }^{30}$ On the other hand, T lymphocytes and cellmediated immunity are essential for the eradication of chlamydial infections. ${ }^{31-34} \mathrm{~T}$ lymphocyte stimulation by C. trachomatis elementary bodies elicits IFN- $\gamma$ production. ${ }^{35}$ IFN- $\gamma$ produced by activated T cells has been shown to inhibit the intracellular growth of Chlamydia ${ }^{36}$ and to participate in the defence against early infection. ${ }^{37}$ In addition, IFN- $\gamma$ exhibits cytotoxic activity against cells infected with C. trachomatis. ${ }^{38}$ Therefore, activation of $\mathrm{T}$ cells could bring about both protective and deleterious effects.

In the current study, helper/inducer $\mathrm{T}$ lymphocytes were greater in number than suppressor/cytotoxic $\mathrm{T}$ lymphocytes, which is similar to the finding of previous reports of inflamed and active trachoma. ${ }^{25,26}$ Two different types of helper/inducer $\mathrm{T}$ cell clones have been identified on the basis of their differing cytokine profile. ${ }^{39}$ Th1 cells produce IL- 2 and IFN- $\gamma$, and mediate several functions associated with cell-mediated immunity, while Th2 cells produce IL-4, IL-5, IL-6 and IL-10 and are more effective in stimulating B cells to produce antibody. Previous studies have demonstrated that cellular immune responses in the local tissues associated with chlamydial infections are dominated by Th1-like responses ${ }^{40,41}$ and intravenous transfer of C. trachomatis-specific Th1 clone induced resolution of murine chlamydial genital infection. ${ }^{32}$ In addition, repeated experimental chlamydial infection of the female fallopian tubes were found to produce Th1-like cytokine response associated with progression to fibrosis. ${ }^{42}$ In previous immunohistochemical studies of conjunctival specimens from patients with active trachoma, we have demonstrated that the epithelial cells expressed MHC class II antigens. ${ }^{3,4}$ It is well known that the expression of MHC class II antigens requires stimulation with IFN- $\gamma^{43}$ produced by activated Th1 cells. However, other soluble factors produced during an immune response have been found to regulate MHC class II expression by tumour cell lines. ${ }^{44}$ On the basis of these findings we may assume that the large preponderance of helper/inducer $\mathrm{T}$ cells observed in the conjunctival biopsies comprised Th1 cells. The pattern of cytokines produced during infection changes over time and correlates with the type and magnitude of tissue injury. In the acute phase of pulmonary tuberculosis induced in mice, a clear predominance of Th1 cells was observed. This was followed by a chronic phase characterised by fibrosis with a Th0 balance due to an equivalent proportion of IL-2- and IL-4-positive cells. ${ }^{45}$ Recently, Igietseme et al..$^{33}$ have demonstrated that $\mathrm{CD}_{8}{ }^{+} \mathrm{T}$ cells may contribute to anti-chlamydial $\mathrm{T}$ cell immunity in vivo. In addition, Starnbach et al. ${ }^{34}$ characterised a cytotoxic T lymphocyte line derived from mice infected with $C$. trachomatis. This line is specific for, and able to lyse, Chlamydia-infected cells, and recognises a peptide epitope present on infected cells in the context of MHC class I molecule. On the basis of these observations cytotoxic $\mathrm{T}$ cells could comprise the major component of $\mathrm{OKT}_{8}{ }^{+}$suppressor/ cytotoxic $\mathrm{T}$ cells detected in conjunctival specimens.

\section{Macrophages and trachoma}

Increased numbers of $\mathrm{KP}_{1}{ }^{+}$macrophages were noted in the conjunctival biopsy specimens from patients with trachoma. Macrophages are important components of the immune response to foreign agents. It has been demonstrated, using an in vitro system, that macrophages inhibit intracellular C. trachomatis replication. ${ }^{46}$ In addition, macrophages play a central role in normal wound healing and pathological fibrosis by virtue of their ability to release a variety of fibrogenic cytokines. ${ }^{30}$ In the present study we have detected cytoplasmic expression of the fibrogenic cytokines IL- $1 \alpha$, IL-1 $\beta$ (discussed above), TNF- $\alpha$ and PDGF by macrophages in the substantia propria. Our results are consistent with previous studies that murine C. trachomatis infection induces TNF- $\alpha$ production. ${ }^{47}$ TNF- $\alpha$ stimulates fibroblast proliferation and collagen synthesis. ${ }^{13,16}$ On the other hand, TNF- $\alpha$ is known to restrict intracellular chlamydial replication. ${ }^{36}$ PDGF is a potent chemoattractant and mitogen for fibroblasts and smooth muscle cells and a stimulator of collagen synthesis by fibroblasts. ${ }^{48-51}$ Several studies have demonstrated that alveolar macrophages from the lungs with pulmonary fibrosis release exaggerated amounts of PDGF, ${ }^{52-55}$ IL- $1^{16,17,56}$ and TNF- $\alpha .{ }^{16,56,57}$ In addition, the mRNA expression of IL- $\beta$, TNF- $\alpha{ }^{16}$ and PDGF $^{55}$ was increased in alveolar macrophages from patients with pulmonary fibrosis. High levels of IL-1 were also produced in unstimulated monocytes from patients with idiopathic myelofibrosis. ${ }^{18}$ These cytokines have the potential to influence the remodelling and fibrosis observed in the conjunctiva of patients with trachoma.

\section{Conclusions}

In conclusion, the present data provide the first direct evidence for the in vivo expression of IL-1 in conjunctival epithelium from patients with trachoma. In addition, conjunctival macrophage activation is suggested by findings of the cytoplasmic expression of IL- $1 \alpha$, IL- $1 \beta$, TNF- $\alpha$ and PDGF. The upregulated local production of these cytokines may contribute to the expansion of connective tissue cells and collagen accumulation in conjunctiva. These cytokines may act alone or in combination with other cytokines, including TGF- $\beta$, to promote conjunctival scarring in trachoma. Further studies to define the role of IL-1 and other cytokines in the pathogenesis of conjunctival scarring in trachoma may lead to new approaches to prevention and treatment. Total eradication of the chlamydial agent, prevention of reinfection, and pharmacological agents 
that interfere with the mechanisms of action of these cytokines would provide a potential therapeutic opportunity for the prevention of fibrosis.

The authors thank Ms Christel Van den Broeck and Mr Hank Cooper for technical assistance, Ms Connie B. Unisa for her secretarial work, and Mr Dustan Kangave for statistical assistance.

\section{References}

1. Dawson CR, Jones BR, Tarizzo ML. Guide to trachoma control in programmes for the prevention of blindness. Geneva: World Health Organization; Albany, NY: WHO Publications Centre USA [distributor], 1981.

2. Taylor HR. Trachoma and inclusion conjunctivitis. In: Strickland G, editor. Hunter's tropical medicine. 7th ed. Philadelphia: Saunders, 1991:288-93.

3. Abu El-Asrar AM, Van den Oord JJ, Geboes K, Missotten L, Emarah MH, Desmet V. Immunopathology of trachomatous conjunctivitis. Br J Ophthalmol 1989;73:276-82.

4. Abu El-Asrar AM, Emarah MH, Van den Oord JJ, Geboes K, Desmet V, Missotten L. Conjunctival epithelial cells infected with Chlamydia trachomatis express HLA-DR antigens [letter]. Br J Ophthalmol 1989;79:399-400.

5. Turner M, Chantry D, Buchan G, Barrett K, Feldman M. Regulation of expression of human IL- $1 \alpha$ and IL-1 $\beta$ genes. J Immunol 1989;143:3556-61.

6. Lonnemann G, Endres S, Van der Meer JW, Cannon JG, Koch $\mathrm{KM}$, Dinarello CA. Differences in the synthesis and kinetics of release of interleukin 1 alpha (IL 1 alpha), IL 1 beta and tumor necrosis factor from human mononuclear cells. Eur J Immunol 1989;19:1531-6.

7. Dinarello CA. Biology of interleukin 1. FASEB J 1988;2:108-15.

8. Li DQ, Tseng SC. Three patterns of cytokine expression potentially involved in epithelial-fibroblast interactions of human ocular surface. J Cell Physiol 1995;163:61-79.

9. Rothermel CD, Schachter J, Lavrich P, Lipsitz EC, Francus T. Chlamydia trachomatis-induced production of interleukin-1 by human monocytes. Infect Immunol 1989;57:2705-11.

0. Magee DM, Smith JG, Bleicker CA, Carter CJ, Bonewald LF, Schacter J, et al. Chlamydia trachomatis pneumonia induces in vivo production of interleukin-1 and -6. Infect Immunol 1992;60:1217-20.

11. Dayer JM, de Rochemonteix B, Burrus B, Demczuk S, Dinarello CA. Human recombinant interleukin-1 stimulates collagenase and prostaglandin $\mathrm{E}_{2}$ production by human synovial cells. J Clin Invest 1986;77:645-8.

12. Heckmann M, Adelmann-Grill BC, Hein R, Krieg T. Biphasic effects of interleukin-1 $\alpha$ on dermal fibroblasts: enhancement of chemotactic responsiveness at low concentrations and of mRNA expression for collagenase at high concentrations. J Invest Dermatol 1993;100:780-4.

13. Elias JA, Freundlich B, Kern JA, Rosenbloom J. Cytokine networks in the regulation of inflammation and fibrosis in the lung. Chest 1990;97:1439-45.

14. Raines EW, Dower SK, Ross R. Interleukin-1 mitogenic activity for fibroblasts and smooth muscle cells is due to PDGF-AA. Science 1989;243:393-6.

15.Schmidt JA, Mezel SB, Cohen D, Green I. Interleukin-1, a potential regulator of fibroblast proliferation. J Immunol 1982;128:2177-82.

16. Zhang Y, Lee TC, Guillemin B, Yu MC, Rom WN. Enhanced IL-1 $\beta$ and tumor necrosis factor- $\alpha$ release and messenger RNA expression in macrophages from idiopathic pulmonary fibrosis or after asbestos exposure. J Immunol 1993;150:4188-96.
17. Kline JN, Schwartz DA, Monick MM, Floerchinger CS, Hunninghake GW. Relative release of interleukin-1 $\beta$ and interleukin-1 receptor antagonist by alveolar macrophages. A study in asbestos-induced lung disease, sarcoidosis, and idiopathic pulmonary fibrosis. Chest 1993;104:47-53.

18. Rameshwar P, Denny TN, Stein D, Gascon P. Monocyte adhesion in patients with bone marrow fibrosis is required for the production of fibrogenic cytokines: potential role for interleukin-1 and TGF- $\beta$. J Immunol 1994;153:2819-30.

19. Kawanami O, Jiang HX, Mochimaru H, Yoneyama H, Kudoh $\mathrm{S}$, Ohkuni $\mathrm{H}$, et al. Alveolar fibrosis and capillary alteration in experimental pulmonary silicosis in rats. Am J Respir Crit Med 1995;151:1946-55.

20. Franko AJ, Sharplin J. Development of fibrosis after lung irradiation in relation to inflammation and lung function in a mouse strain prone to fibrosis. Radiat Res 1994;140:347-55.

21. Hinglais N, Heudes D, Nicoletti A, Mandet C, Laurent M, Bariety J, et al. Colocalization of mycocardial fibrosis and inflammatory cells in rats. Lab Invest 1994;70:286-94.

22. Wahl SM. The role of lymphokines and monokines in fibrosis. Ann N Y Acad Sci 1985;460:224-31.

23. Levitt D, Danen R, Bard J. Both species of Chlamydia and two biovars of Chlamydia trachomatis stimulate mouse B lymphocytes. J Immunol 1986;136:4249-54.

24. Levitt D, Danen R. Development and regulation of Chlamydia-responsive murine B lymphocytes. J Immunol 1987;138:3468-74.

25. Burd EM, Tabbara KF, Nasr AM, Taylor PB. Conjunctival lymphocyte subsets in trachoma. Int Ophthalmol 1988;12:53-7.

26. Reacher MH, Pe'er J, Rapoza PA, Whittum-Hudson JA, Taylor HR. T cells and trachoma: their role in cicatricial disease. Ophthalmology 1991;98:334-41.

27. Wahl SM, Hunt DA, Allen JB, Wilder RL, Paglia WL, Hand AR. Bacterial cell wall-induced hepatic granulomas: an in vivo model of $\mathrm{T}$ cell-dependent fibrosis. J Exp Med 1986;163:884-902.

28. Barbul A. Role of T cell-dependent immune system in wound healing. Prog Clin Biol Res 1988;266:161-75.

29. Wahl SM,Allen JB. T lymphocyte-dependent mechanisms of fibrosis. Prog Clin Biol Res 1988;266:147-60.

30. Kovacs EJ, Di Pietro LA. Fibrogenic cytokines and connective tissue production. FASEB J 1994;8:854-61.

31. Su H, Caldwell HD. $\mathrm{CD}_{4} \mathrm{~T}$ cells play a significant role in adaptive immunity to Chlamydia trachomatis infection of the mouse genital tract. Infect Immun 1995;63:3302-8.

32. Igietseme JU, Ramsey KH, Magee DM, Williams DM, Kincy TJ, Rank RG. Resolution of murine chlamydial genital infection by the adoptive transfer of a biovar-specific Th1 lymphocyte clone. Reg Immunol 1993;5:317-24.

33. Igietseme JU, Magee DM, Williams DM, Rank RG. Role for $\mathrm{CD}_{8}{ }^{+} \mathrm{T}$ cells in antichlamydial immunity defined by Chlamydia-specific T-lymphocyte clones. Infect Immun 1994;63:5195-7.

34. Starnbach MN, Bevan MJ, Lampe MF. Protective cytotoxic T lymphocytes are induced during murine infection with Chlamydia trachomatis. J Immunol 1994;153:5183-9.

35. Fitzpatrick DR, Wie J, Webb D, Bonfiglioli R, Gardner ID, Mathews JD, et al. Preferential binding of Chlamydia trachomatis to subsets of human lymphocytes and induction of interleukin-6 and interferon-gamma. Immunol Cell Biol 1991;69:337-48.

36. Summersgill JT, Sahney NN, Gaydos CA, Quinn TC, Ramirez JA. Inhibition of Chlamydia pneumoniae growth in HEp-2 cells pretreated with gamma interferon and tumor necrosis factor alpha. Infect Immun 1995;63:2801-3.

37. McCafferty MC, Maley SW, Entrican G, Buxton D. The importance of interferon- $\gamma$ in an early infection of Chlamydia psittaci in mice. Immunology 1994;81:631-6. 
38. Byrne GI, Grubbs B, Marshall TJ, Schachter J, Williams DM. Gamma interferon-mediated cytotoxicity related to murine Chlamydia trachomatis infection. Infect Immun 1988;56:2023-7.

39. Mosmann TR, Coffman RL. Th1 and Th2 cells: different patterns of lymphokine secretion lead to different functional properties. Annu Rev Immunol 1989;7:145-73.

40. Cain TK, Rank RG. Local Th1-like responses are induced by intravaginal infection of mice with the mouse pneumonitis biovar of Chlamydia trachomatis. Infect Immun 1995;63:1784-9.

41. Simon AK, Seipelt E, Wu P, Wenzel B, Braun J, Sieper J. Analysis of cytokine profiles in synovial $\mathrm{T}$ cell clones from Chlamydia reactive arthritis patients: predominance of the Th1 subset. Clin Exp Immunol 1993;94:122-6.

42. Van Voorhis WC, Barrett LK, Sweeney YT, Kuo CC, Patton DL. Repeated Chlamydia trachomatis infection of Macaca nemestrina fallopian tubes produce a Th1-like cytokine response associated with fibrosis and scarring. Infect Immun 1997;65:2175-82.

43. Abu El-Asrar AM, Van den Oord JJ, Billiau A, Desmet V, Emarah MH, Missotten L. Recombinant interferon-gamma induces HLA-DR expression on human corneal epithelial and endothelial cells in vitro: a preliminary report. $\mathrm{Br} \mathrm{J}$ Ophthalmol 1989;73:587-90.

44. Callahan GN. Soluble factors produced during an immune response regulate Ia antigen expression by murine adenocarcinoma and fibrosarcoma cells. J Immunol 1984;132:2649-57.

45. Hernandez-Pando R, Orozcoe H, Sampieri A, Povon L, Velasquillo C, Larriva-Sahd J, et al. Correlation between the kinetics of Th1, Th2 cells and pathology in a murine model of experimental pulmonary tuberculosis. Immunology 1996;89:26-33.

46. Manor E, Sarov I. Inhibition of Chlamydia trachomatis replication in HEp-2 cells by human monocyte-derived macrophages. Infect Immun 1988;56:3280-4.

47. Williams DM, Bonewald LF, Roodman GD, Byrne GI, Magee DM, Schachter J. Tumor necrosis factor alpha is a cytotoxin induced by murine Chlamydia trachomatis infection. Infect Immun 1989;57:1351-5.
48. Ross R, Raines EW, Bowen-Pope DF. The biology of platelet derived growth factor. Cells 1986;46:155-69.

49. Westermark B. The molecular and cellular biology of platelet-derived growth factor. Acta Endocrinol 1990;123:131-42.

50. Grotendorst GR, Seppa HE, Kleinman HK, Martin GR. Attachment of smooth muscle cells to collagen and their migration toward platelet-derived growth factor. Proc Natl Acad Sci USA 1981;78:3669-72.

51. Seppa HE, Grotendorst GR, Seppa S, Schiffmann E, Martin GR. Platelet-derived growth factor is chemotactic for fibroblasts. J Cell Biol 1982;92:584-8.

52. Martinet Y, Rom WR, Grothendorst GR, Martin GR, Crystal RG. Exaggerated spontaneous release of platelet-derived growth factor by alveolar macrophages from patients with idiopathic pulmonary fibrosis. N Engl J Med 1987;317:202-9.

53. Nagaoka I, Trapnell BC, Crystal RG. Upregulation of platelet-derived growth Factor-A and -B gene expression in alveolar macrophages of individuals with idiopathic pulmonary fibrosis. J Clin Invest 1990;85:2023-7.

54. Harmon KR, Witkop CJ, White JG, King RA, Peterson M, Moore D, et al. Pathogenesis of pulmonary fibrosis: plateletderived growth factor precedes structural alterations in the Hermansky-Pudlak syndrome. J Lab Clin Med 1994;123:617-27.

55. Antoniades HN, Bravo MA, Avila RE, Galanopoulos T, Neville-Golden J, Maxwell M, et al. Platelet-derived growth factor in idiopathic pulmonary fibrosis. J Clin Invest 1990;86:1055-64.

56. Phan SH, Kunkel SL. Lung cytokine production in bleomycin-induced pulmonary fibrosis. Exp Lung Res 1992;18:29-43.

57. Everson MP, Chandler DB. Changes in distribution, morphology, and tumor necrosis factor- $\alpha$ secretion of alveolar macrophage subpopulations during the development of bleomycin-induced pulmonary fibrosis. Am J Pathol 1992;140:503-12. 